\title{
Comparison of maximal hyperemic myocardial blood flow response between regadenoson and adenosine: A quantitative positron emission tomography $13 \mathrm{~N}$-ammonia study
}

Georgios Christopoulos ${ }^{1}$, John P Bois ${ }^{1}$, Brad J Kemp ${ }^{2}$, John W Askew ${ }^{1}$, Martin Rodriguez-Porcel ${ }^{1}$, Nandan Anavekar ${ }^{1}$, Raymond J Gibbons ${ }^{1}$, Geoffrey B Johnson ${ }^{2}$ and Panithaya Chareonthaitawee ${ }^{*}$

${ }^{1}$ Department of Cardiovascular Medicine, Mayo Clinic, Rochester, Minnesota, USA

${ }^{2}$ Department of Radiology, Mayo Clinic, Rochester, Minnesota, USA

\begin{abstract}
Background: The purpose of this study was to compare peak regadenoson vs. peak adenosine absolute myocardial blood flow (MBF) and myocardial flow reserve (MFR) measurements by positron emission tomography (PET) 13N-ammonia (13N-NH3) in healthy human subjects.

Methods: A prospective assessment of 12 healthy subjects without any history of cardiovascular or pulmonary disorders was conducted. Each subject underwent three PET 13N-NH3 dynamic emission acquisitions: resting, fixed-dose regadenoson $(0.4 \mathrm{mg} / 5 \mathrm{ml} \mathrm{IV})$, and weight-based adenosine $(140 \mu \mathrm{g} / \mathrm{kg} / \mathrm{min}$; order randomized according to subject's birth year). Global and regional MBF were calculated using a two-compartment model that included metabolite and left and right ventricle spill-over corrections and adjustment for tissue density to yield values of $\mathrm{MBF}$ in $\mathrm{ml} / \mathrm{min} / \mathrm{g}$. MFR was calculated as hyperemic MBF/resting MBF.

Results: Mean age and BMI were $44 \pm 8$ years and $26.1 \pm 4.3 \mathrm{~kg} / \mathrm{m}^{2}$ respectively. Global and regional hyperemic PET 13N-NH3 MBF and MFR were not significantly different between regadenoson vs. adenosine (global peak MBF: $2.90 \pm 0.67$ vs. $3.25 \pm 1.11 \mathrm{ml} / \mathrm{min} / \mathrm{g}, P=0.28 ;$ MFR: $3.64 \pm 0.69$ vs. $4.18 \pm 1.17, P$ $=0.39)$. Heart rate, systolic, and diastolic blood pressures were not significantly different between regadenoson vs. adenosine $(98 \pm 16$ vs. $93 \pm 15$ beats $/$ minute, $P=$ $0.51 ; 130 \pm 17$ vs. $132 \pm 23 \mathrm{mmHg}, P=0.31 ; 72 \pm 11$ vs. $75 \pm 17 \mathrm{mmHg}, P=0.08$, respectively).

Conclusions: In this study regadenoson produced a PET 13N-NH3 MBF response and MFR that was comparable to adenosine. Further randomized studies with larger patient samples are warranted to validate this result.
\end{abstract}

Abbreviations: LV: Left Ventricle; MBF: Myocardial Blood Flow; MFR: Myocardial Flow Reserve; MPI: Myocardial Perfusion Imaging; MRI: Magnetic Resonance Imaging; PET: Positron Emission Tomography; RV: Right Ventricle; SPECT: Single Photon Emission Computed Tomography; TAC: Time-Activity Curve

\section{Introduction}

For several decades, dipyridamole and adenosine were the main vasodilator stress agents in radionuclide myocardial perfusion imaging (MPI) worldwide due to their potent hyperemic effects. In 2008, the United States Food and Drug Administration (FDA) approved regadenoson, a selective $\mathrm{A} 2 \mathrm{~A}$ adenosine agonist, for use as a pharmacologic stress agent in single photon emission computed tomography (SPECT) MPI. Since then, regadenoson has gained widespread use for radionuclide MPI in the United States due to its many advantages [1,2]. Regadenoson has single-bolus administration with no need for weight-based dose adjustment or infusion equipment, rapid onset and termination of action, and better subjective tolerability [1]. Regadenoson also has a safer profile in moderate to severe airway disease, compared other vasodilator stress agents [3-5]. At the same time, regadenoson has comparable safety and non-inferior ischemia detection as compared to adenosine and dipyridamole in clinical trials [6-11].
The peak hyperemic absolute myocardial blood flow (MBF) responses to dipyridamole and adenosine are well-documented using positron emission tomography (PET) MBF quantification in normal human volunteers [12-24]. However, there is a paucity of data on regadenoson PET MBF, particularly when using the tracer $13 \mathrm{~N}$-ammonia (13N-NH3). The primary objective of the present study was to quantify regadenoson PET MBF and myocardial flow reserve (MFR) using the tracer $13 \mathrm{~N}-\mathrm{NH} 3$ and to compare these measurements with adenosine PET MBF and MFR in healthy human subjects.

\section{Methods}

\section{Study Population}

The study was approved by the Mayo Institutional Review Board and all participants gave informed and written consent prior to enrolment in the study. Twelve healthy volunteers ( 6 women and 6 men) were

*Correspondence to: Panithaya Chareonthaitawee, Mayo Clinic, 200 First Street SW, Rochester, MN 55905, USA, Tel: (507) 284-1648; Fax: (507) 266-0228; E-mail: chareonthaitawee.panithaya@mayo.edu

Key words: PET, myocardial blood flow, myocardial perfusion imaging, regadenoson, adenosine, vasodilator stress

Received: March 22, 2019; Accepted: April 09, 2019; Published: April 12, 2019 
recruited by public advertising. Prior to the PET studies, each subject underwent a detailed history and physical examination by study staff (PC). All subjects gave a history of normal effort tolerance and had no symptoms. Participants were excluded if they had a history of any cardiovascular or pulmonary disorders, were smokers, or were taking any medications [25]. All subjects had a normal cardiac and pulmonary examination, and a normal resting electrocardiogram. Based on the above all subjects were determined to have a low probability of coronary artery disease. Figure 1 illustrates the study protocol.

\section{Rest and stress PET MPI protocol}

Subjects were instructed to have a light meal at least 4 hours before and to abstain from caffeine-containing products for 24 hours prior to the PET MPI, respectively [26]. Scans were performed on the Advance PET scanner (GE Healthcare, Waukesha, Wisconsin). The scanner operated in 2-D mode (septa in place), enabling the acquisition of 35 planes of data over a $550 \mathrm{~mm}$ field of view with a $148.8 \mathrm{~mm}$ axial depth. With the subject in the scanner, a 4-minute 2-bed scout image was first obtained to determine the optimal position of the heart within the field of view. A 12-minute transmission scan using two germanium-68 sources was then performed for subsequent attenuation correction of the resting emission images. For measurement of resting MBF, $13 \mathrm{~N}$ $\mathrm{NH} 3(20 \mathrm{mCi} \pm 10 \%$ of dose) was administered intravenously over 20 seconds followed by a saline flush. Dynamic acquisition was performed simultaneously with the $13 \mathrm{~N}-\mathrm{NH} 3$ injection using the following acquisition parameters: $5 \times 2,20 \times 3,9 \times 10,4 \times 20,3 \times 300$ frames $\times$ seconds. Hemodynamic measurements were recorded two minutes after administration of $13 \mathrm{~N}-\mathrm{NH} 3$. Median administered dose per patient was $20.51 \mathrm{mCi}(20.05,21.00)$.

The order of the regadenoson and adenosine infusions was randomized based on the subject's birth year (even, regadenoson first; odd, adenosine first). Following a 50-minute period of $13 \mathrm{~N}-\mathrm{NH} 3$ decay, regadenoson $(0.4 \mathrm{mg} / 5 \mathrm{ml} \mathrm{IV})$ was administered intravenously over 10 seconds, followed immediately by saline flush, then $13 \mathrm{~N}-\mathrm{NH} 3$ (20 $\mathrm{mCi} \pm 10 \%$ dose) injection and an additional saline flush (within one minute of injection with regadenoson). Dynamic PET acquisition was repeated as above for measurement of regadenoson-induced hyperemic MBF. Subject assessment, electrocardiographic monitoring, and hemodynamic measurements were performed during and up to 10 minutes after regadenoson infusion.

Following a second 50-minute period of decay, adenosine (140 $\mu \mathrm{g} /$ $\mathrm{kg} / \mathrm{min}$ ) was administered intravenously over 6 minutes. Three minutes after the start of adenosine infusion, $13 \mathrm{~N}-\mathrm{NH} 3(20 \mathrm{mCi} \pm 10 \%$ dose $)$ was administered and dynamic acquisition performed as described. Subject assessment, electrocardiographic monitoring, and hemodynamic measurements were performed during and up to 6 minutes after adenosine infusion. A second transmission scan was obtained after the second stress PET acquisition. Patients were excluded from the analysis per protocol if they had ST segment changes, even if they did not have ischemia in the images. This was based on prior literature demonstrating that patients with exercise induced ST changes may have a higher likelihood of CAD even if images are normal [25].

\section{PET image analysis}

An experienced operator blinded to the stress agent performed quantification of MBF. Studies were also assessed visually and rated for quality control by a consensus of two experienced readers using summed dynamic images reconstructed in standard views, displayed using in-house customized software, and interpreted according to the guidelines of the American Society of Nuclear Cardiology [27].

PET sinograms were corrected for attenuation, scatter, random events, dead time, and radioactive decay and reconstructed into a $22-\mathrm{cm}$ field of view $(128 \times 128$ matrix $)$ centred on the myocardium. For quantification of MBF, PET images were transferred to a workstation and analyzed with commercial software (version 2.8;

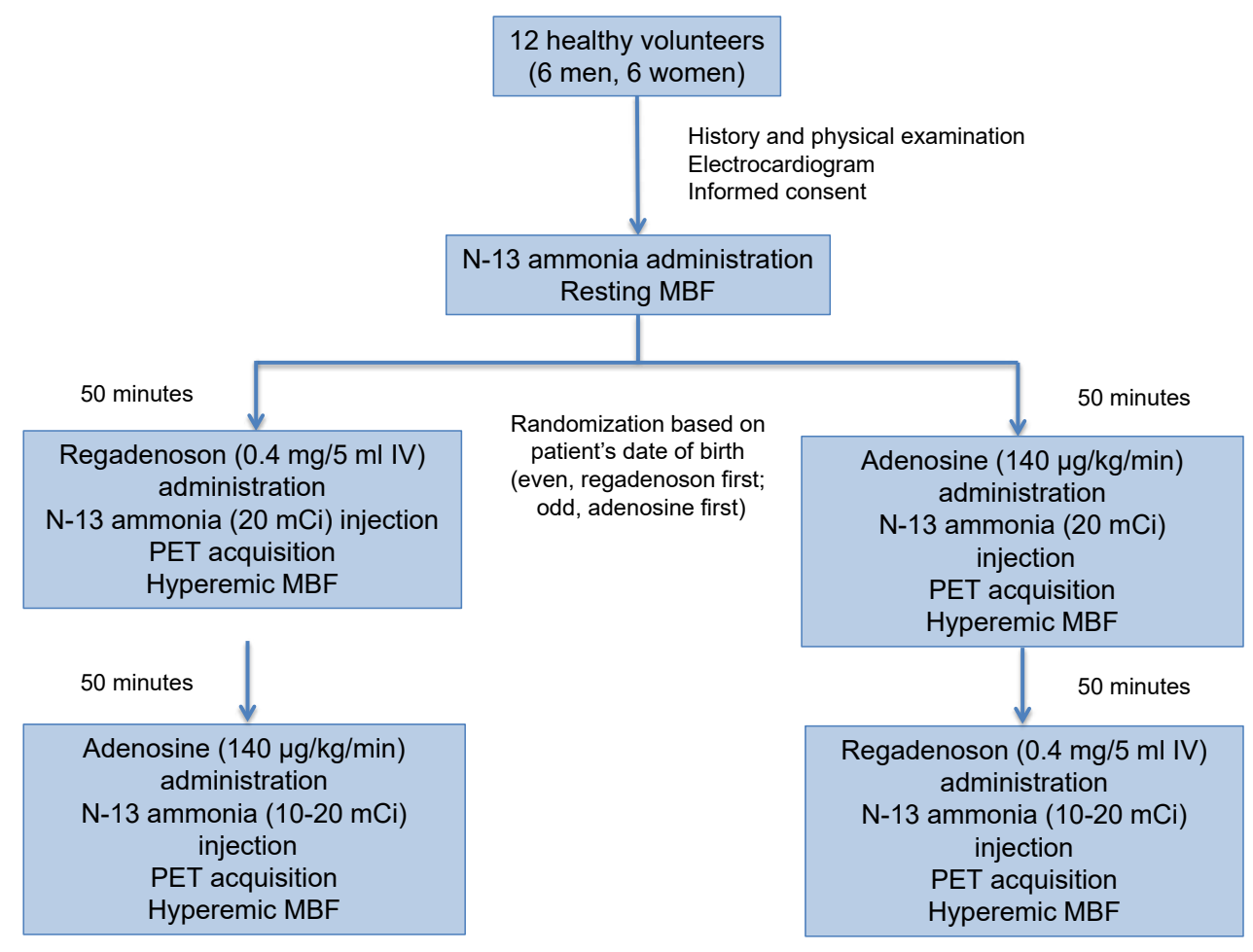

Figure 1. Study protocol 
Christopoulos G (2019) Comparison of maximal hyperemic myocardial blood flow response between regadenoson and adenosine: A quantitative positron emission tomography $13 \mathrm{~N}$-ammonia study

PMOD Technologies LLC $^{\odot}$ ). Using a combination of long- and short-axis images, the operator defined the apex and the base of the left ventricular (LV) myocardium as previously described [28]. The software then automatically defined 4 myocardial regions of interest (ROIs) in the apical planes and 6 myocardial ROIs in both mid and basal LV planes to produce a total of 16 myocardial segments. The LV and right ventricular (RV) blood-pool ROIs were also defined manually on 3 short-axis planes. Time-activity curves (TACs) were generated for the LV, RV and myocardial ROIs. The LV input function and myocardial TACs were input into a one-compartment model [29] that includes metabolite and left and right ventricle spillover corrections to yield values of regional and global $\mathrm{MBF}$ in $\mathrm{mL} / \mathrm{min} / \mathrm{mL}$ [28]. In order to minimize the effects of metabolites, only the first $4 \mathrm{~min}$ of the $13 \mathrm{~N}-\mathrm{NH} 3 \mathrm{TACs}$ were used in the modelling. For comparison with previously reported values, MBF values were divided by the density of myocardial tissue $(1.04 \mathrm{~g} / \mathrm{mL})$ to express $\mathrm{MBF}$ values in $\mathrm{mL} / \mathrm{min} / \mathrm{g}$ [22]. Myocardial flow reserve (MFR) was calculated using the equation hyperemic MBF/resting MBF.27

\section{Statistical analysis}

Data were expressed as mean \pm standard deviation (continuous variables) or percentages (categorical variables). Since our analysis included less than 25 patient pairs, statistical comparisons were performed using a matched Wilcoxon sign rank test. Prior to the study, power calculations demonstrated that with 12 subjects, this study would have $80 \%$ power to detect a difference in global MBF of 0.8 between the regadenoson and adenosine measurements. Two-sided $\mathrm{p}$ values of less than 0.05 were considered statistically significant. Stat View statistical software version 5 (SAS Institute, Cary, NC) was used for all analyses.

\section{Results}

\section{Hemodynamic and electrocardiographic responses}

The mean age of the 12 subjects in the study was $44 \pm 8$ years. Fifty percent of subjects were male. The mean BMI was $26.1 \pm 4.3$. There were no significant differences in resting or peak heart rate, systolic, or diastolic blood pressures, change in the parameters between baseline and hyperemia, or in peak rate-pressure product between regadenoson and adenosine groups (Table 1).

There were no adverse events in either vasodilator stress group but one subject in each vasodilator group, both women, experienced $1.5 \mathrm{~mm}$ horizontal ST-segment depression during hyperemia. As per protocol, these two subjects with electrocardiographic changes were excluded from undergoing the second vasodilator study. No arrhythmias were observed in either vasodilator stress group.

\section{Myocardial blood flow and myocardial flow reserve}

After randomization based on birth year, 6 patients underwent regadenoson PET followed by adenosine PET and 6 patients underwent adenosine PET followed by regadenoson PET. Resting global MBF was $0.80 \pm 0.17 \mathrm{~mL} / \mathrm{min} / \mathrm{g}$ and increased to $2.90 \pm 0.67 \mathrm{~mL} / \mathrm{min} / \mathrm{g}$ with regadenoson and $3.25 \pm 1.11 \mathrm{~mL} / \mathrm{min} / \mathrm{g}$ with adenosine $(P=0.28$, Figure 2A). Global MFR was calculated at $3.64 \pm 0.69$ with regadenoson and $4.18 \pm 1.17$ with adenosine $(P=0.39$, Figure $2 B)$. Segmental MBF and MFR during pharmacologic vasodilation was not statistically different between the regadenoson and adenosine groups (Table 2).

\section{Discussion}

The present study demonstrates that regadenoson induces a maximal hyperemic $13 \mathrm{~N}-\mathrm{NH} 3 \mathrm{MBF}$ effect that is nearly three times
Table 1. Hemodynamics and electrocardiographic findings

\begin{tabular}{|c|c|c|c|}
\hline & $\begin{array}{l}\text { Regadenoson } \\
\mathrm{n}=11^{*}\end{array}$ & $\begin{array}{l}\text { Adenosine } \\
\mathbf{n}=11^{*}\end{array}$ & $\boldsymbol{P}$ \\
\hline $\begin{array}{l}\text { Heart rate (beats/minute) } \\
\text { Rest } \\
\text { Hyperemic } \\
\text { Maximum increase }\end{array}$ & $\begin{array}{l}62 \pm 10 \\
98 \pm 16 \\
35 \pm 13\end{array}$ & $\begin{array}{l}60 \pm 9 \\
93 \pm 15 \\
35 \pm 11\end{array}$ & $\begin{array}{l}0.28 \\
0.51 \\
0.73\end{array}$ \\
\hline $\begin{array}{l}\text { Blood pressure }(\mathrm{mmHg}) \\
\text { Rest systolic } \\
\text { Hyperemic systolic } \\
\text { Maximum change } \\
\text { Rest diastolic } \\
\text { Hyperemic diastolic } \\
\text { Maximum change }\end{array}$ & $\begin{array}{l}136 \pm 18 \\
130 \pm 17 \\
9 \pm 9 \\
74 \pm 10 \\
72 \pm 11 \\
1 \pm 6\end{array}$ & $\begin{array}{l}136 \pm 18 \\
132 \pm 23 \\
10 \pm 16 \\
76 \pm 11 \\
75 \pm 17 \\
5 \pm 11\end{array}$ & $\begin{array}{l}0.67 \\
0.31 \\
0.31 \\
0.57 \\
0.08 \\
0.08\end{array}$ \\
\hline $\begin{array}{l}\text { Rate-pressure product } \\
\text { Rest } \\
\text { Hyperemic } \\
\text { Maximum change }\end{array}$ & $\begin{array}{l}7500 \pm 1345 \\
12819 \pm 2981 \\
5209 \pm 2439\end{array}$ & $\begin{array}{l}7263 \pm 1234 \\
12464 \pm 4037 \\
5338 \pm 3037\end{array}$ & $\begin{array}{l}0.29 \\
0.08 \\
0.55\end{array}$ \\
\hline Ischemic ECG findings (n) & 1 & 1 & - \\
\hline
\end{tabular}

*1 subject in each group had $1.5 \mathrm{~mm}$ ST-segment depression and therefore was excluded from the second vasodilator test

Values are mean \pm standard deviation

ECG: electrocardiogram

Table 2. Myocardial blood flow and myocardial flow reserve between regadenoson and adenosine

\begin{tabular}{|l|l|l|l|l|}
\hline & $\begin{array}{l}\text { Rest } \\
(\mathbf{n = 1 2})\end{array}$ & $\begin{array}{l}\text { Stress } \\
\text { Regadenoson } \\
(\mathbf{n = 1 1 )}\end{array}$ & $\begin{array}{l}\text { Stress } \\
\text { Adenosine } \\
(\mathbf{n = 1 1 )}\end{array}$ & $\boldsymbol{P}^{*}$ \\
\hline $\begin{array}{l}\text { Myocardial blood } \\
\text { flow (mL/min/g) }\end{array}$ & & & & \\
Global & $0.80 \pm 0.17$ & $2.90 \pm 0.67$ & $3.25 \pm 1.11$ & 0.28 \\
Septal & $0.92 \pm 0.22$ & $3.09 \pm 0.85$ & $3.83 \pm 1.41$ & 0.20 \\
Anterior & $0.72 \pm 0.15$ & $2.35 \pm 0.45$ & $2.56 \pm 0.80$ & 0.51 \\
Inferior & $0.79 \pm 0.17$ & $3.26 \pm 1.62$ & $3.55 \pm 1.33$ & 0.33 \\
Lateral & $0.77 \pm 0.16$ & $2.91 \pm 0.60$ & $2.96 \pm 1.12$ & 0.88 \\
\hline $\begin{array}{l}\text { Myocardial flow } \\
\text { reserve }\end{array}$ & & & & \\
Global & - & & & \\
\hline Septal & - & $3.64 \pm 0.69$ & $4.18 \pm 1.17$ & 0.39 \\
Anterior & - & $3.38 \pm 0.70$ & $4.39 \pm 1.59$ & 0.11 \\
Inferior & - & $4.02 \pm 1.06$ & $3.69 \pm 1.01$ & 0.72 \\
Lateral & - & $3.87 \pm 0.95$ & $4.60 \pm 1.28$ & 0.33 \\
\hline
\end{tabular}

Values are mean \pm standard deviation

*P value for comparison of stress myocardial blood flow or myocardial flow reserve between regadenoson and adenosine (1 patient in each group had ST depression and, therefore, paired-Wilcoxon analysis was performed in 10 patients)

the resting flow and was not statistically different from adenosine. The additions of the present study to the existing literature include paired analysis, the selection of healthy individuals as the study population and comparison with adenosine, which has not been previously performed in the same setting. This study provides a sample PET $13 \mathrm{~N}-\mathrm{NH} 3$ protocol with regadenoson and MBF measurements, that may serve as a reference for those in clinical practice who are considering or who are starting a PET MPI practice with PET 13N-NH3 with regadenoson.

Comparison of our results with those from prior studies is limited by differences in imaging modality, patient population and, in PET stress imaging, radioactive tracers used and acquisition protocol. More recent studies of PET stress imaging report a 1.34 to 2.88 -fold increase in MBF after administration of regadenoson using either 82-Rubidium (82Rb) or $13 \mathrm{~N}-\mathrm{NH} 3.7,9,10,30-32$ (Table 3). Our study demonstrates a nearly three-fold increase in hyperemic global MBF (rest $0.80 \pm$ $0.17 \mathrm{~mL} / \mathrm{min} / \mathrm{g}$ and stress $2.90 \pm 0.67 \mathrm{~mL} / \mathrm{min} / \mathrm{g}$ ) and a higher MFR $(3.64 \pm 0.69)$ with regadenoson compared to prior studies that using PET to determine MBF (Table 3). This difference may have several explanations. First, healthy individuals are more likely to have higher 

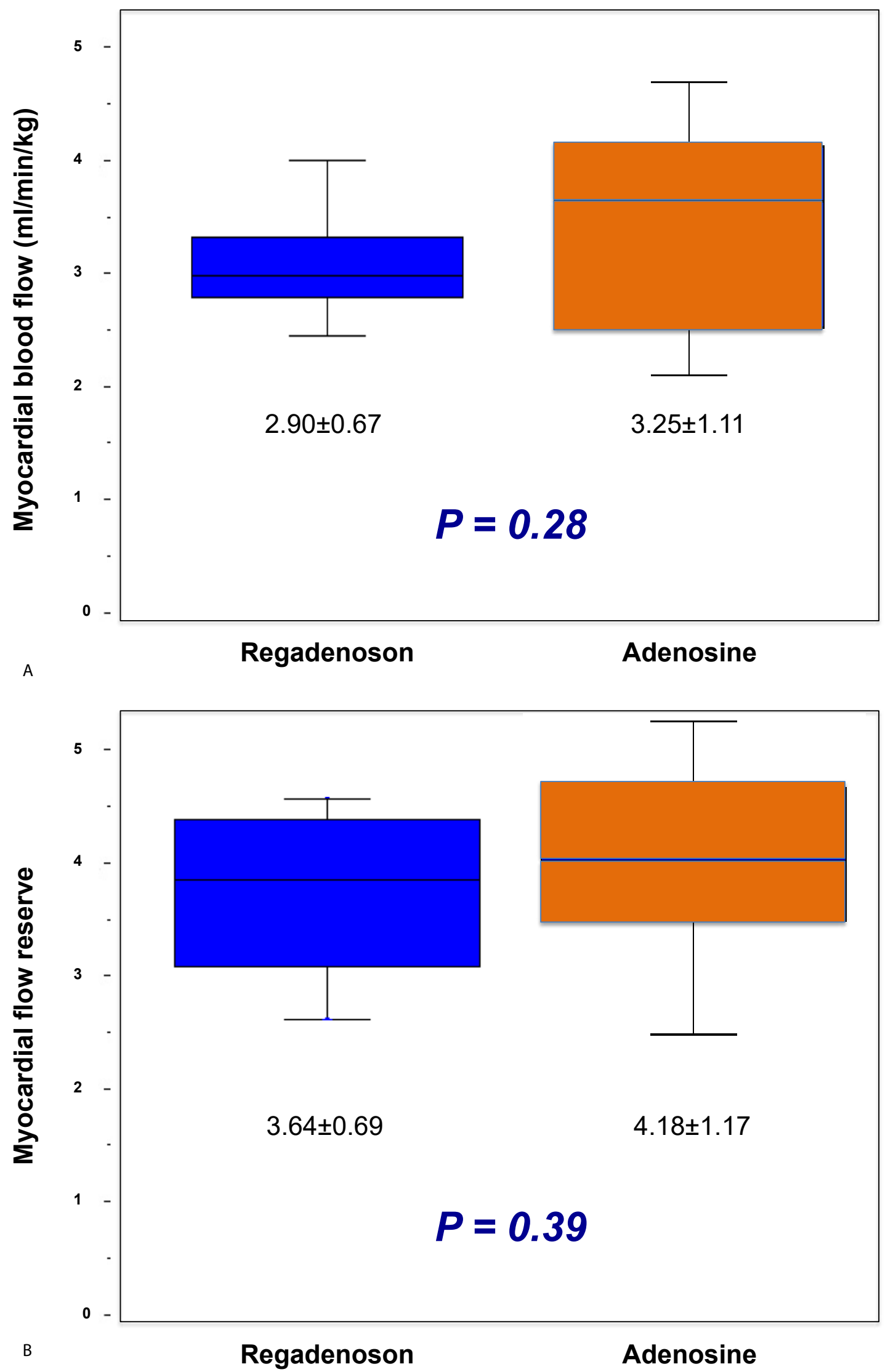

Figure 2. Box plots of global hyperemic myocardial blood flow (A) and myocardial flow reserve (B) with regadenoson and adenosine. Values represent means and standard deviation. 
Christopoulos G (2019) Comparison of maximal hyperemic myocardial blood flow response between regadenoson and adenosine: A quantitative positron emission tomography $13 \mathrm{~N}$-ammonia study

Table 3. Comparison table of studies reporting myocardial blood flow during the hyperemic phase of regadenoson PET MPI

\begin{tabular}{|c|c|c|c|c|c|c|c|}
\hline Study & n & Age (years) & PET tracer & Resting MBF & MBF after regadenoson & MFR & Comments \\
\hline Goudarzi et al. (2011) & 52 & $52 \pm 11$ & ${ }^{82} \mathrm{Rb}$ & $0.79 \pm 0.24$ & $2.19 \pm 0.64$ & $2.89 \pm 0.76$ & $\begin{array}{l}\text { Compared with dipyridamole in healthy } \\
\text { subjects }\end{array}$ \\
\hline Bravo et al (2012) & 57 & $51 \pm 12$ & ${ }^{13} \mathrm{~N}-\mathrm{NH}_{3}$ & $0.92 \pm 0.22$ & $1.81 \pm 0.44$ & $2.02 \pm 0.53$ & $\begin{array}{l}\text { Compared with dipyridamole in patients } \\
\text { with HCM }\end{array}$ \\
\hline Van Tosh et al (2013) & 205 & $69 \pm 13$ & ${ }^{82} \mathrm{Rb}$ & $0.86 \pm 0.54$ & $1.65 \pm 0.95$ & $2.12 \pm 1.00$ & $\begin{array}{l}\text { Related MBF and MFR to ischemia- } \\
\text { induced LV dysfunction }\end{array}$ \\
\hline Johnson et al. (2015) & 126 & $60 \pm 9$ & ${ }^{82} \mathrm{Rb}$ & $0.76 \pm 0.17$ to $1.04 \pm 0.32$ & $1.34 \pm 0.36$ to $2.33 \pm 0.57$ & $1.77 \pm 0.37$ to $2.55 \pm 0.56$ & $\begin{array}{l}\text { Compared with dipyridamole (paired test), } \\
\text { MBF was obtained in }-15 \mathrm{~s} \text { to }+80 \mathrm{~s} \text { after } \\
\text { regadenoson administration (highest at }+55 \mathrm{~s} \text { ) }\end{array}$ \\
\hline Valenta et al (2016) & 29 & $68(55-72)$ & ${ }^{13} \mathrm{~N}-\mathrm{NH}_{3}$ & $\begin{array}{l}0.71(0.67-0.80) \text { to } 0.75 \\
(0.68-0.81)\end{array}$ & $\begin{array}{l}1.44(1.23-1.72) \text { to } 1.60 \\
(1.37-1.82)\end{array}$ & $\begin{array}{l}1.97(1.71-2.36) \text { to } 2.23 \\
(1.76-2.37)\end{array}$ & $\begin{array}{l}\text { Patients with known or suspected CAD, } \\
\text { correlated MBF with FFR, (MBF highest } \\
\text { in regions without stenosis } \geq 50 \% \text { ) }\end{array}$ \\
\hline Pampaloni et al (2017) & 12 & $55 \pm 7$ & ${ }^{13} \mathrm{~N}-\mathrm{NH}_{3}$ & $1.33 \pm 0.31$ & $2.68 \pm 0.84$ & $2.07 \pm 0.74$ & $\begin{array}{l}\text { Patients with orthotopic heart } \\
\text { transplantation and no history of post } \\
\text { transplant myocardial ischemia }\end{array}$ \\
\hline Present study & 11 & $44 \pm 8$ & ${ }^{13} \mathrm{~N}-\mathrm{NH}_{3}$ & $0.80 \pm 0.17$ & $2.90 \pm 0.67$ & $3.64 \pm 0.69$ & $\begin{array}{l}\text { Compared with adenosine in healthy } \\
\text { subjects }\end{array}$ \\
\hline
\end{tabular}

Values are mean \pm standard deviation or median (quartile range)

PET: positron emission tomography; MPI: myocardial perfusion imaging; MBF: myocardial blood flow; MFR: myocardial flow reserve; FFR: fractional flow reserve; HCM: hypertrophic cardiomyopathy; LV: left ventricle; CAD: coronary artery disease; $82 \mathrm{Rb}=$ rubidium-82; $13 \mathrm{~N}-\mathrm{NH} 3$ : ammonia-13

absolute MBF and MFR compared to patients with underlying cardiac pathology Second, the PET tracer (13N-NH3 or $82 \mathrm{Rb})$ likely has a significant impact on absolute MBF, underscoring the importance of using the same tracer as reference when determining the baseline or hyperemic values in clinical practice. Lastly, the timing of regadenoson infusion and delivery of PET perfusion tracer has a significant impact on absolute MBF and MFR values, as demonstrated by Johnson et al. [9] who reported stress MBF of $2.33 \pm 0.57$ with tracer delivery at 55 seconds vs. $1.79 \pm 0.44$ at 10 seconds after regadenoson administration using $82 \mathrm{Rb}$.

The use of regadenoson for radionuclide MPI has several advantages over other vasodilator stress agents. First, unlike adenosine and dipyridamole, regadenoson administration does not require an intravenous infusion pump or dose-adjustment according to the patient's body weight. Second, regadenoson's rapid onset of action renders it a highly suitable agent for PET MPI, where the administration of the pharmacologic stress agent must be near-simultaneous with image acquisition due to the short physical half-life of $13 \mathrm{~N}-\mathrm{NH} 3$ and $82 \mathrm{Rb}$ (9.9 and 1.3 minutes, respectively). Third, subject tolerability with regadenoson is also more favourable compared to adenosine [33]. The intensity of side effects of other vasodilator drugs may lead to greater patient and respiratory motion, which could possibly introduce imaging artifacts and reduce diagnostic accuracy [1,34]. Finally, regadenoson has an advantage in patients with a history of stable asthma and/or stable chronic obstructive pulmonary disease, in which adenosine and dipyridamole may be less tolerated [3-5].

Currently, $82 \mathrm{Rb}$ and $13 \mathrm{~N}-\mathrm{NH} 3$ are the only radionuclide tracers approved by the United States Food and Drug Administration (FDA) with $18 \mathrm{~F}$-Flurpiridaz currently being investigated in a phase III trial [35]. Among the nuclear perfusion tracers, $13 \mathrm{~N}-\mathrm{NH} 3$ provides consistently high-quality images, high diagnostic accuracy, and the lowest patient total body radiation exposure among radionuclide MPI studies. Compared to the other FDA approved PET perfusion tracer, $82 \mathrm{Rb}, 13 \mathrm{~N}-\mathrm{NH} 3$ has not been as widely used in clinical PET MPI due to the need for an on-site cyclotron. However, availability of small dedicated cyclotrons for $13 \mathrm{~N}-\mathrm{NH} 3$ may increase availability of this radiotracer. Furthermore, the recognition by the American Society of Nuclear Cardiology and the Society of Nuclear Medicine and Molecular
Imaging of the significant underutilization of PET MPI relative to its demonstrated advantages for patients being assessed for suspected clinically important CAD is anticipated to increase the utilization of PET MPI.

\section{Limitations}

The results of this study should be interpreted within the context of its limitations. First, the study included a small number of subjects, thereby decreasing statistical power and potentially underestimating the difference between the two vasodilators. Second, the study was conducted at a single-center, using a single PET scanner and software. This may limit generalizability to other institutions and equipment, but as the same time it provides a consistent approach to data collection. Third, patients with suspected or demonstrated CAD were excluded from the study, limiting extrapolation of results to that patient population. Fourth, the PET myocardial perfusion images were acquired at the same time point after regadenoson infusion for all study subjects. As such, there is uncertainty that after a 50-minute delay MBF has returned to the baseline. Because previous studies have demonstrated variability of $\mathrm{MBF}$ based on the timing of the image acquisition to the regadenoson bolus, it is important to consider this aspect when applying these results in other imaging settings [10]. Fifth, 2D rather than the more contemporary $3 \mathrm{D}$ PET acquisition was performed in this study. However, it has been shown on the GE Advance PET system that 2D and 3D cardiac PET imaging is comparable [36]. Finally, our study findings do not apply to patients with ST segment changes, since those patients were excluded.

In conclusion, in this preliminary study including healthy human subjects, regadenoson induced a maximal hyperemic flow that was nearly three times the resting flow and was not statistically different from adenosine. Larger studies are warranted in the future to validate this result.

\section{Acknowledgements}

\section{The study was supported by Astellas Pharma, Inc.}

The study was presented in part at the 17th Annual Scientific Session of the American Society of Nuclear Cardiology, September 8, 2012, Baltimore, Maryland. 
Christopoulos G (2019) Comparison of maximal hyperemic myocardial blood flow response between regadenoson and adenosine: A quantitative positron emission tomography $13 \mathrm{~N}$-ammonia study

\section{References}

1. Palani G, Ananthasubramaniam K (2013) Regadenoson: review of its established role in myocardial perfusion imaging and emerging applications. Cardiol Rev 21: 42-48. [Crossref]

2. Al Jaroudi W, Iskandrian AE (2009) Regadenoson: a new myocardial stress agent. $J$ Am Coll Cardiol 54: 1123-1130. [Crossref]

3. Leaker BR, O'Connor B, Hansel TT, Barnes PJ, Meng L, et al. (2008) Safety of regadenoson, an adenosine $\mathrm{A} 2 \mathrm{~A}$ receptor agonist for myocardial perfusion imaging, in mild asthma and moderate asthma patients: a randomized, double-blind, placebocontrolled trial. J Nucl Cardiol 15: 329-336. [Crossref]

4. Thomas GS, Tammelin BR, Schiffman GL, Marquez R, Rice DL, et al. (2008) Safety of regadenoson, a selective adenosine A2A agonist, in patients with chronic obstructive pulmonary disease: A randomized, double-blind, placebo-controlled trial (RegCOPD trial). J Nucl Cardiol 15:319-328. [Crossref]

5. Husain Z, Palani G, Cabrera R, Karthikeyan AS, Dhanalakota S, et al. (2012) Hemodynamic response, arrhythmic risk, and overall safety of regadenoson as a pharmacologic stress agent for myocardial perfusion imaging in chronic obstructive pulmonary disease and bronchial asthma patients. Int J Cardiovasc Imaging 28:18411849. [Crossref]

6. Mahmarian JJ, Peterson LE, Xu J, Cerqueira MD, Iskandrian AE, et al. (2015) Regadenoson provides perfusion results comparable to adenosine in heterogeneous patient populations: a quantitative analysis from the ADVANCE MPI trials. $J \mathrm{Nucl}$ Cardiol 22: 248-261. [Crossref]

7. Bravo PE, Pozios I, Pinheiro A, Merrill J, Tsui BM, et al. (2012) Comparison and effectiveness of regadenoson versus dipyridamole on stress electrocardiographic changes during positron emission tomography evaluation of patients with hypertrophic cardiomyopathy. Am J Cardiol 110: 1033-1039. [Crossref]

8. Cullom SJ, Case JA, Courter SA, McGhie AI, Bateman TM (2013) Regadenoson pharmacologic rubidium-82 PET: a comparison of quantitative perfusion and function to dipyridamole. J Nucl Cardiol 20: 76-83. [Crossref]

9. Goudarzi B, Fukushima K, Bravo P, Merrill J, Bengel FM (2011) Comparison of the myocardial blood flow response to regadenoson and dipyridamole: a quantitative analysis in patients referred for clinical $82 \mathrm{Rb}$ myocardial perfusion PET. Eur J Nucl Med Mol Imaging 38: 1908-1916. [Crossref]

10. Johnson NP, Gould KL (2015) Regadenoson versus dipyridamole hyperemia for cardiac PET imaging. JACC Cardiovasc Imaging 8: 438-447. [Crossref]

11. Mahmarian JJ, Cerqueira MD, Iskandrian AE, Bateman TM, Thomas GS, et al. (2009) Regadenoson induces comparable left ventricular perfusion defects as adenosine: a quantitative analysis from the ADVANCE MPI 2 trial. JACC Cardiovasc Imaging 2: 959-968. [Crossref]

12. Chan SY, Brunken RC, Czernin J, Porenta G, Kuhle W, et al. (1992) Comparison of maximal myocardial blood flow during adenosine infusion with that of intravenous dipyridamole in normal men. J Am Coll Cardiol 20: 979-985. [Crossref]

13. Dunet V, Klein R, Allenbach G, Renaud J, deKemp RA, et al. (2016) Myocardial blood flow quantification by $\mathrm{Rb}-82$ cardiac PET/CT: A detailed reproducibility study between two semi-automatic analysis programs. $\mathrm{J} \mathrm{Nucl}$ Cardiol 23: 499-510. [Crossref]

14. Gewirtz H (2012) PET measurement of adenosine stimulated absolute myocardia blood flow for physiological assessment of the coronary circulation. $\mathrm{J} \mathrm{Nucl} \mathrm{Cardiol}$ 19: 347-354. [Crossref]

15. Nkoulou R, Fuchs TA, Pazhenkottil AP, Kuest SM, Ghadri JR, et al. (2016) Absolute Myocardial Blood Flow and Flow Reserve Assessed by Gated SPECT with CadmiumZinc-Telluride Detectors Using 99mTc-Tetrofosmin: Head-to-Head Comparison with 13N-Ammonia PET. J Nucl Med 57: 1887-1892. [Crossref]

16. Schepis T, Gaemperli O, Treyer V, Valenta I, Burger C, et al. (2007) Absolute quantification of myocardial blood flow with $13 \mathrm{~N}$-ammonia and 3-dimensional PET. $J$ Nucl Med 48:1783-1789. [Crossref]

17. Mamede M, Tadamura E, Hosokawa R, Ohba M, Kubo S, et al. (2005) Comparison of myocardial blood flow induced by adenosine triphosphate and dipyridamole in patients with coronary artery disease. Ann Nucl Med 19: 711-717. [Crossref]

18. Mishra RK1, Dorbala S, Logsetty G, Hassan A, Heinonen T, et al. (2005) Quantitative relation between hemodynamic changes during intravenous adenosine infusion and the magnitude of coronary hyperemia: implications for myocardial perfusion imaging. $J$ Am Coll Cardiol 45: 553-558. [Crossref]

19. Klein R, Ocneanu A, Renaud JM, Ziadi MC, Beanlands RSB, et al. (2018) Consistent tracer administration profile improves test-retest repeatability of myocardial blood flow quantification with ${ }^{82} \mathrm{Rb}$ dynamic PET imaging. J Nucl Cardiol 25: 929-941. [Crossref]
20. Ziadi MC, Dekemp RA, Williams K, Guo A, Renaud JM, et al. (2012) Does quantification of myocardial flow reserve using rubidium-82 positron emission tomography facilitate detection of multivessel coronary artery disease? $\mathrm{J} \mathrm{Nucl} \mathrm{Cardiol}$ 19:670-80. [Crossref]

21. El Fakhri G, Kardan A, Sitek A, Dorbala S, Abi-Hatem N, et al. (2009) Reproducibility and accuracy of quantitative myocardial blood flow assessment with (82)Rb PET: comparison with (13)N-ammonia PET. J Nucl Med 50:1062-1071. [Crossref]

22. Schafers KP, Spinks TJ, Camici PG, Bloomfield PM, Rhodes CG, et al. (2002) Absolute quantification of myocardial blood flow with $\mathrm{H}(2)(15) \mathrm{O}$ and 3-dimensional PET: an experimental validation. $J$ Nucl Med 43: 1031-40. [Crossref]

23. Frouin F, Merlet P, Bouchareb Y, Frouin V, Dubois-Randé JL, et al. (2001) Validation of myocardial perfusion reserve measurements using regularized factor images of $\mathrm{H}(2)$ (15)O dynamic PET scans. J Nucl Med 42: 1737-1746. [Crossref]

24. Iida H, Yokoyama I, Agostini D, Banno T, Kato T, et al. (2000) Quantitative assessment of regional myocardial blood flow using oxygen-15-labelled water and positron emission tomography: a multicentre evaluation in Japan. Eur J Nucl Med 27: 192-201. [Crossref]

25. Diamond GA, Forrester JS (1979) Analysis of probability as an aid in the clinical diagnosis of coronary-artery disease. $N$ Engl J Med 300: 1350-1358. [Crossref]

26. Gaemperli O, Schepis T, Koepfli P, Siegrist PT, Fleischman S, et al. (2008) Interaction of caffeine with regadenoson-induced hyperemic myocardial blood flow as measured by positron emission tomography: a randomized, double-blind, placebo-controlled crossover trial. J Am Coll Cardiol 51: 328-329. [Crossref]

27. Schelbert HR, Beanlands R, Bengel F, Knuuti J, Dicarli M, et al. (2003) PET myocardia perfusion and glucose metabolism imaging: Part 2-Guidelines for interpretation and reporting. J Nucl Cardiol 10: 557-571. [Crossref]

28. Chareonthaitawee P, Christenson SD, Anderson JL, Kemp BJ, Hodge DO, et al. (2006) Reproducibility of measurements of regional myocardial blood flow in a model of coronary artery disease: Comparison of $\mathrm{H} 215 \mathrm{O}$ and $13 \mathrm{NH} 3$ PET techniques. $\mathrm{J} \mathrm{Nucl}$ Med 47: 1193-1201. [Crossref]

29. DeGrado TR, Hanson MW, Turkington TG, Delong DM, Brezinski DA, et al. (1996) Estimation of myocardial blood flow for longitudinal studies with 13N-labeled ammonia and positron emission tomography. J Nucl Cardiol 3: 494-507. [Crossref]

30. Pampaloni MH, Shrestha UM, Sciammarella M, Seo Y, Gullberg GT, et al. (2017) Noninvasive PET quantitative myocardial blood flow with regadenoson for assessing cardiac allograft vasculopathy in orthotopic heart transplantation patients. $J \mathrm{Nucl}$ Cardiol 24: 1134-1144. [Crossref]

31. Valenta I, Antoniou A, Marashdeh W, Leucker T, Kasper E, et al. (2017) PETmeasured longitudinal flow gradient correlates with invasive fractional flow reserve in CAD patients. Eur Heart J Cardiovasc Imaging 18: 538-548. [Crossref]

32. Van Tosh A, Reichek N, Palestro CJ, Nichols KJ (2016) Effect of Outflow Tract Contributions to 82Rb-PET Global Myocardial Blood Flow Computations. J Nucl Med Technol 44: 78-84. [Crossref]

33. Iskandrian AE, Bateman TM, Belardinelli L, Blackburn B, Cerqueira MD, et al. (2007) Adenosine versus regadenoson comparative evaluation in myocardial perfusion imaging: results of the ADVANCE phase 3 multicenter international trial. $\mathrm{J} \mathrm{Nucl}$ Cardiol 14: 645-658. [Crossref]

34. Johnson SG, Peters S (2010) Advances in pharmacologic stress agents: focus on regadenoson. J Nucl Med Technol 38: 163-171. [Crossref]

35. Dilsizian V, Taillefer R (2012) Journey in evolution of nuclear cardiology: will there be another quantum leap with the F-18-labeled myocardial perfusion tracers? JACC Cardiovasc Imaging 5: 1269-84. [Crossref]

36. Knesaurek K, Machac J, Krynyckyi BR, Almeida OD (2003) Comparison of 2-dimensional and 3-dimensional $82 \mathrm{Rb}$ myocardial perfusion PET imaging. $\mathrm{J} \mathrm{Nucl}$ Med 44: 1350-1356. [Crossref]

Copyright: (C)2019 Christopoulos G. This is an open-access article distributed under the terms of the Creative Commons Attribution License, which permits unrestricted use, distribution, and reproduction in any medium, provided the original author and source are credited. 